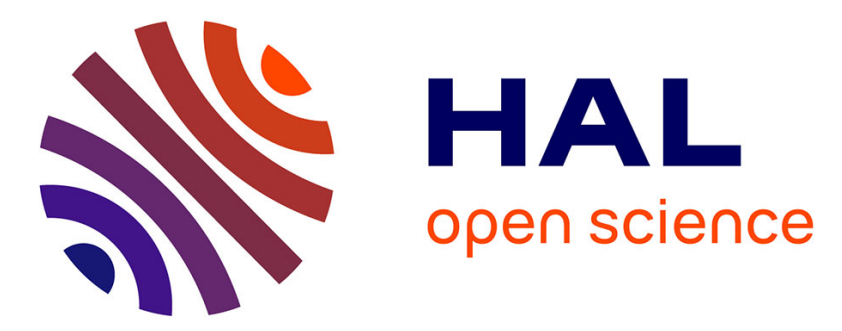

\title{
Optimising efficacy and reducing toxicity of anticancer radioimmunotherapy
}

Eric Deutsch, Cyrus Chargari, Lorenzo Galluzzi, Guido Kroemer

\section{To cite this version:}

Eric Deutsch, Cyrus Chargari, Lorenzo Galluzzi, Guido Kroemer. Optimising efficacy and reducing toxicity of anticancer radioimmunotherapy. Lancet Oncology, 2019, 20, pp.e452 - e463. 10.1016/S1470-2045(19)30171-8 . hal-03488042

\section{HAL Id: hal-03488042 \\ https://hal.science/hal-03488042}

Submitted on 20 Dec 2021

HAL is a multi-disciplinary open access archive for the deposit and dissemination of scientific research documents, whether they are published or not. The documents may come from teaching and research institutions in France or abroad, or from public or private research centers.
L'archive ouverte pluridisciplinaire HAL, est destinée au dépôt et à la diffusion de documents scientifiques de niveau recherche, publiés ou non, émanant des établissements d'enseignement et de recherche français ou étrangers, des laboratoires publics ou privés.

\section{다(1) $\$$}

Distributed under a Creative Commons Attribution - NonCommercial| 4.0 International 


\section{Optimizing efficacy and reducing toxicity of anticancer}

\section{radioimmunotherapy}

Eric Deutsch $^{1,2,3}$, Cyrus Chargari ${ }^{1,3,4}$, Lorenzo Galluzzi ${ }^{5,6,7,8}$ and Guido Kroemer ${ }^{8,9,10,11,12,13,14^{*}}$

${ }^{1}$ Department of Radiation Oncology, Gustave Roussy Comprehensive Cancer Center, Villejuif, France; ${ }^{2}$ Faculté de Médecine, Université Paris Sud/Paris Saclay, Paris, France; ${ }^{3}$ INSERM, U1030, Paris, France; ${ }^{4}$ French Military Health Academy, Ecole du Val-de-Grâce, Paris, France; ${ }^{5}$ Department of Radiation Oncology, Weill Cornell Medical College, New York, NY, USA; ${ }^{6}$ Sandra and Edward Meyer Cancer Center, New York, NY, USA $;{ }^{7}$ Department of Dermatology, Yale School of Medicine, New Haven, CT, USA; ${ }^{8}$ Université Paris Descartes/Paris V, Paris, France; ${ }^{9}$ Equipe labellisée par la Ligue contre le cancer, Université Paris Descartes, Université Paris Diderot, Sorbonne Paris Université Cité, INSERM U1138, Centre de Recherche des Cordeliers, Paris, France; ${ }^{10}$ Metabolomics and Cell Biology Platforms, Institut Gustave Roussy, Villejuif, France; ${ }^{11}$ Pôle de Biologie, Hôpital Européen Georges Pompidou, AP-HP, Paris, France; ${ }^{12}$ Suzhou Institute for Systems Biology, Chinese Academy of Sciences, Suzhou, China; ${ }^{13}$ Department of Women's and Children's Health, Karolinska University Hospital, Stockholm, Sweden.

Titles: Eric Deutsch, MD, PhD, Full Professor; Cyrus Chargari, MD, PhD, Full Professor.; Lorenzo Galluzzi, PhD, Assistant Professor; Guido Kroemer, MD, PhD, Full Professor.

*Correspondence to Guido Kroemer: Centre de Recherche des Cordeliers, 15 rue de l'Ecole de Médecine, 75006 Paris, France; (kroemer@orange.fr)

Running title: Radiotherapy and immunotherapy combinations for cancer therapy.

Keywords: abscopal response; dendritic cells; type I interferon; proton therapy; regulatory T cells; tumor-draining lymph nodes.

Disclosures: Dr. Deutsch reports grants and personal fees from Roche Genentech, grants from Servier, grants from AstraZeneca, grants and personal fees from Merck Seriono, grants from BMS, grants from MSD, outside the submitted work. Dr. Chargari has been invited to national 
or international congresses by Takeda, and operates as (principal) investigator on clinical or preclinical trials for TherAguix, Roche and Servier. Dr. Galluzzi reports grants from Phosplatin, grants from Lytix, personal fees from The Luke Heller TECPR2 Foundation, personal fees from Astra Zeneca, other from Phosplatin, other from The Luke Heller TECPR2 Foundation, personal fees from OmniSEQ, personal fees from VL47, outside the submitted work. Dr. Kroemer reports grants and personal fees from Bayer Healthcare, grants from Genentech, grants from Glaxo Smyth Kline, grants and personal fees from Lytix Pharma, grants from PharmaMar, grants from Sotio, grants from Vasculox, other from Bristol Myers Squibb Foundation France, other from everImmune, other from Samsara therapeutics, outside the submitted work. Laurence Zitvogel, Guido Kroemer's spouse, has the following financial relationships to disclose, all outside the submitted work: Scientific advisory boards at Lytix Pharma, EpiVax, NeoVax andTusk Pharma; Administrative board at Transgene; Grant/Research support from Glaxo Smith Kline, Merus, Tusk Roche and Incyte; Founder and shareholder: everImmune. 


\begin{abstract}
Immunotherapy is radically changing the clinical management of patients affected by an increasingly wide array of tumors. However, a limited percentage of patients achieve long-term clinical benefits from immunotherapy employed as a standalone treatment, calling for the development of combinatorial regimens. Radiation therapy (RT) stands out as a particularly promising candidate in this setting, reflecting not only its established safety profile, but also the potential ability of RT to mediate robust immunostimulatory effects that may synergize with immunotherapy in systemic tumor control. However, optimal radioimmunotherapy regimens may call for the redefinition of conventional RT doses and fractionation schedules. Here, we discuss current approaches to improve the efficacy and reduce the toxicity of radioimmunotherapy for the management of cancer.
\end{abstract}




\section{Introduction}

More than half of cancer patients are treated with radiation therapy (RT), which has become a mainstay for the management of several, locally advanced solid tumors. Over the past few decades, significant technical improvements fostered the widespread dissemination of multiple variants of RT, including intensity modulated RT (IMRT), image-guided RT, as well as intraor extracranial stereotactic RT. ${ }^{1}$ These developments rapidly translated into the possibility of local dose escalation, resulting in increased cure rates in patients affected with some tumors like prostate and cervical cancer. ${ }^{2}$ Moreover, it has become possible to deliver high doses of RT with unprecedented anatomical precision, allowing for partial breast irradiation and longterm local control of brain and lung metastases. ${ }^{3,4}$ Alongside, the decreased collateral damage to radiosensitive organs enabled by IMRT has reduced the risk of long-term sequelae, including xerostomia for patients with head and neck squamous cell carcinoma (HNSCC), bowel toxicity for subjects with gynecological tumors, and poor cosmetic outcome for women with breast cancers, just to mention a few examples.,

While these technical ameliorations have spread rapidly over the recent years, the development of therapies to complement RT has somehow stagnated since the 1990s, when several clinical trials demonstrated that chemoradiation - i.e., the association of RT and cytotoxic chemotherapy - can result in improved local tumor control, organ preservation and patient survival in some oncological settings. ${ }^{7}$ Since the dissemination of these results, no major trial has successfully challenged the idea that cisplatin, 5-fluoruracil, mitomycin $\mathrm{C}$ and temozolomide should be used to improve the therapeutic efficacy of RT. Indeed, contrasting with the expectations nourished by preclinical studies, combinatorial regimens involving targeted anticancer agents and RT failed to provide superior clinical benefits as compared to conventional chemoradiation. ${ }^{8-10}$ There are multiple possible causes for these deceptive clinical 
results including, on a case-by-case basis, the validity of preclinical proofs of concepts, the impact of combinatorial therapies on normal tissues, the absence of reliable biomarkers for patient selection, and technical aspects linked to radiation delivery. These shortcomings are likely to be overcome by an improved communication among radiation oncologists, medical oncologists, statisticians, pharmacologists, and experts in imaging and translational research.

The realization that the immune system can provide a major contribution to therapeutic responses to $\mathrm{RT}^{11}$ provided a strong rationale in support of clinical trials combining (multiple variants of) immunotherapy with (various forms of) RT. Such an intensive wave of investigation on radioimmunotherapy has recently culminated in the approval of chemoradiation plus the immune checkpoint blocker (ICB) durvalumab for the treatment of unresectable stage III non-small cell lung carcinoma (NSCLC), ${ }^{12}$ which turned out to be effective and well tolerated despite a previous report alerting about potential lung toxicity. ${ }^{13}$ Currently, more than 150 clinical trials are open to explore the combination of standard, fulldose (chemo)radiation plus immunotherapy, ${ }^{14}$ mostly in the form of ICBs targeting CD274 (best known as PD-L1), like durvalumab itself, avelumab and atezolizumab, programmed cell death 1 (PDCD1, best known as PD-1), like pembrolizumab, nivolumab and cemiplimab, or cytotoxic $\mathrm{T}$ lymphocyte-associated protein 4 (CTLA4), like ipilimumab (source https://clinicaltrials.gov/). It can be anticipated that many of these combinatorial regimens will enable superior therapeutic responses as they subside toxicities, hopefully both in the short and long term, ultimately resulting in the cure of patients with previously untreatable tumors, especially in the setting of oligometastatic disease (Figure 1).

Classical radiation biology has investigated the efficacy of RT mostly in vitro and in xenograft models, i.e., in immunodeficient mice bearing human cancer cell lines, two models that completely neglect potential contribution of the immune system to therapeutic effects. ${ }^{15}$ This has imposed a largely cancer cell-autonomous view of the biology of RT, positing that the 
response to RT (and hence the likelihood of complete disease eradication) are directly proportion to the radiation dose and the consequent degree of DNA damage overcoming the repair capability of the cell ${ }^{16}$. This model has fostered a large number of dose-escalation studies, which were successful in some indications, such as prostate and cervical cancer, ${ }^{2}$ but failed to meet expectation in many others, such as NSCLC, esophageal tumors and brain cancers. ${ }^{17}$ The modern conceptual paradigm rather postulates that RT is particularly efficient when its elicits tumor-targeting immune responses. ${ }^{18}$ The major corollary of this shift in perspective is that RT should be administered in doses and schedules that are optimally suitable for eliciting anticancer immunity. As the maximum tolerated dose (MTD) often inhibits or kills immune cells involved in tumor control alongside malignant cells, RT delivered at the MTD generally fails to induce efficient immune responses against cancer, implying a non-linear dose-effect relationship. ${ }^{19}$ Thus, the implementation of modern radioimmunotherapy regimens calls for novel strategies to improve efficacy and limit toxicity, which we discuss in this review. 


\section{Immunological parameters affecting acute and late RT effects}

The side effects of RT generally manifest in a biphasic manner, reflecting both the intensity of the treatment and the organs exposed to direct or scattered irradiation. ${ }^{20}$ The acute phase, which is characterized by local atrophy and inflammation, originates from a wave of cell death driven by RT in tissues with a high mitotic index, such as the epithelium of the oral cavity and the gastrointestinal trait or the hematopoietic system, and hence tends to resolve a few weeks after treatment. ${ }^{21}$ The chronic phase typically starts around 3 months post-RT and involves vascular alterations, persistent oxidative stress, chronic hypoxia, fibroblasts activation potentially leading to fibrosis, and permanent loss of tissue function. ${ }^{22}$ Numerous preclinical studies suggest that the immune system not only participates in the therapeutic effects of RT, but also contributes to both acute and chronic RT toxicities. ${ }^{23}$ Consistent with this notion, deletion of intercellular adhesion molecule 1 (Icam1), which codes for an endothelial cell surface molecule involved in leukocyte extravasation, inhibits both acute inflammatory responses and chronic fibrotic changes in the lungs of mice subjected to thorax irradiation. ${ }^{24} \mathrm{~A}$ similar anti-fibrotic response can be achieved upon depletion of interstitial macrophages with a monoclonal antibody specific for colony stimulating factor 1 receptor (CSF1R). ${ }^{25}$ Moreover, radiationinduced pneumonitis occurring in mice after total body irradiation (TBI) can be suppressed by thymectomy and further restored by the adoptive transfer of splenocytes. ${ }^{26}$ Thus, multiple immune effector cells can contribute to the toxicity of RT. Of note, macrophage depletion with CSF1- or CSF1R-targeting agents has also been shown to improve anticancer immune responses driven by RT (especially in the context of PD-L1 blockade), which the tendency of RT (especially at low doses) to favor the polarization of macrophages towards an immunosuppressive phenotype. ${ }^{27,28}$ Taken together, these observations suggest that targeting macrophages may provide a dual benefit to patients receiving RT: an improved therapeutic response couple to limited toxicity. 
The recruitment of immunosuppressive cells to irradiated organs and their activation is orchestrated by several immunomodulatory molecules released in response to RT. Transforming growth factor beta 1 (TGFB1, best known as TGF- $\beta 1$ ), a cytokine with pleiotropic effects, is pivotal in this context. ${ }^{29}$ TGF- $\beta 1$ signaling increases consistently in irradiated tissues, reflecting not only an increased secretion of the latent form of the protein, but also an increased availability of bioactive TGF- $\beta 1 .^{29}$ On binding to its cognate receptor, which is expressed by a variety of cell types including immune cells and fibroblasts, TGF- $\beta 1$ mediates robust immunosuppressive effects and favors the secretion of collagen, hence favoring fibrosis. ${ }^{29}$ In line with this notion, strategies aimed at inhibiting TGF- $\beta 1$ synergize with ICBs ${ }^{30}$ and $\mathrm{RT}^{31}$ in the control of experimental tumors in mice, at least in part by improving the access of lymphocytes to malignant lesions. Along similar lines, chemical inhibitors of TGF- $\beta 1$ signaling attenuate lung fibrosis in mice receiving RT to the thorax. ${ }^{32}$ Thus, although efficacy in early clinical trial testing this paradigm was rather deceptive, ${ }^{33}$ perhaps reflecting the ability of TGF- $\beta 1$ to inhibit epithelial cell proliferation, ${ }^{34}$ it may be interesting to introduce TGF- $\beta 1$ inhibitors into multimodal treatments including radioimmunotherapy.

Irradiated tissues also expose or secrete large amounts of damage-associated molecular patterns (DAMPs), a heterogeneous group of endogenous molecules that are normally invisible to the immune system owing to their intracellular localization. ${ }^{35}$ On release into the extracellular microenvironment, however, DAMPs can bind to a variety pattern recognition receptors (PRRs) involved in the innate immune response to invading pathogens, including Toll-like receptor (TLRs), hence favoring the establishment of local inflammation. ${ }^{36}$ DAMPs such as the nonhistone chromatin-binding protein high mobility group B1 (HMGB1) and mitochondrial DNA (mtDNA) have been attributed an etiological role in inflammatory conditions including some cardiomyopathies and systemic inflammatory response syndrome (SIRS), largely reflecting their ability to recruit and activate granulocytes. ${ }^{37}$ Consistent with this notion, extracellular 
mtDNA is increased in patient with idiopathic pulmonary fibrosis, ${ }^{38}$ and chemical antagonists of C-X-C motif chemokine receptor 1 (CXCR1) and CXCR2 (which prevent the accumulation of neutrophils in irradiated lung) limit RT-induced fibrosis in mice. ${ }^{39}$ Further corroborating a role for DAMP signaling in the acute and late toxicity of RT, multiple TLR5 agonists have been shown to inhibit RT-driven mucositis, dermatitis, pneumonitis and fibrosis in mice ${ }^{40}$. The precise mechanisms whereby TLR5 agonism (rather than antagonism) mediates radioprotective effects remain elusive.

RT also increases the amounts of MHC Class I and II molecules exposed on the plasma membrane, hence rendering irradiated cells more susceptible to immune recognition. ${ }^{41}$ Supporting a role for this mechanism in the side effects of RT, patients receiving TBI can develop auto-immune disorders accompanied by autoreactive lymphocyte infiltration of the irradiated tissue. ${ }^{42}$ Importantly such immune reactions cannot originate from overt tissue damage and abundant DAMP release, as the RT doses employed are too low to cause cell death. ${ }^{42}$ That said, both TBI and thoracic RT have also been shown to promote the expansion of immunosuppressive $\mathrm{CD} 4{ }^{+} \mathrm{CD} 25^{+} \mathrm{FOXP} 3^{+}$regulatory $\mathrm{T}\left(\mathrm{T}_{\mathrm{REG}}\right)$ cells that potentially attenuate autoimmune reactions driven by $\mathrm{CD}^{+}$helper $\mathrm{T}$ cells $\mathrm{s}^{43,44}$, a mechanism that may depend (at least partially) on epidermal Langerhans cells. ${ }^{45}$ Intriguingly, an immunosuppressive effect that could not be linked to the extent of lymphopenia was documented in mice receiving total lymphoid irradiation (TLI) plus TBI (as compared to TLI alone as early as in 1984, when little was known about the immunobiology of $\mathrm{T}_{\mathrm{REG}}$ and Langerhans cells. ${ }^{46}$ The possibility to harness the immunosuppressive activity of $\mathrm{T}_{\mathrm{REG}}$ cells to limit the inflammatory side effects of RT has attracted considerable attention in the past, ${ }^{44,47}$ but is progressively being abandoned. Conversely, efforts remain focused on conventional radioprotectors, including reactive oxygen species scavenger (e.g., amifostine), molecules that favor epithelial reconstitution (e.g., palifermin), and systemic anti-inflammatory drugs (e.g., aspirin, celecoxib). ${ }^{48}$ 
Importantly, most (if not all) the molecular and cellular mechanisms that underlie the toxicity of RT are also responsible for its therapeutic activity. Thus, cancer cells exposed to cytotoxic doses of RT undergo a potently immunostimulatory cell death variant that has been named immunogenic cell death (ICD). ${ }^{49}$ ICD is characterized by the activation of multiple adaptive stress responses in dying cells that culminate with the exposure or release of DAMPs imping on the regulation of local and systemic homeostasis. ${ }^{41}$ Such stress responses encompass (but may not be limited to): (1) the unfolded protein response at the endoplasmic reticulum (ER), culminating with the exposure of several ER chaperones on the surface of dying cells; (2) autophagy, enabling the release of high levels of ATP from dying cells; and (3) a pathogen-like response involving the detection of ectopic RNA and DNA molecules, culminating with the secretion of type I interferon. ${ }^{50}$ The spatiotemporally coordinated release of these and other DAMPs from cancer cells succumbing to RT enables the recruitment and activation of BATF3dependent dendritic cells (DCs), ultimately resulting in the cross-priming of tumor-specific cytotoxic T lymphocytes (CTLs). ${ }^{35}$ Such a robust response, which involves freshly recruited CTLs as well as tumor-resident CTLs, and is under tonic inhibition by PD-1 and TGF- $\beta$ signaling, ${ }^{51-53}$ can drive not only the eradication of radioresistant cancer cells in the irradiated lesions, but potentially attack non-irradiated metastases (at least in mice and in a limited fraction of patients), a phenomenon commonly referred to as abscopal response. ${ }^{54}$ Further supporting the immunological nature of this process, abscopal responses can be abolished in mice lacking $\mathrm{CD}^{+} \mathrm{T}$ cells as well as in mice in which type I IFN signaling is inhibited ${ }^{11,55}$ and have been observed at increased frequency in patients concomitantly treated with immunotherapy ${ }^{56,57}$ Of note, DAMPs are not the only commonality between the toxicity and therapeutic activity of RT. Rather, the ability of RT to alter vascular permeability in support of local inflammation, ${ }^{58,59}$ and to increase MHC Class I and II exposure are also involved in disease control. ${ }^{41}$ 
What are therefore the determinants of RT efficacy versus toxicity? Accumulating preclinical and clinical data suggest that there at least 3 major parameters at play in this setting: (1) dose and fractionation; (2) irradiated volume; and (3) sequence of administration (in the context of combinatorial regimens).$^{18}$ Finally, since both the efficacy and toxicity of RT rely (at least in part) on the immune system, the overall immunological competence of the host and the factors that determine it should not be underestimated. Such factors encompass not only purely endogenous parameters such as sex, age and polymorphisms in immunity-relevant genes, but also elements at the interface between the individual and the microenvironment, such as the composition of the gut microbiome and the presence of an ongoing infection, and purely exogenous influences, such as the concomitant or recent exposure to immunosuppressive drugs. $^{14}$

Optimal radioimmunotherapy regimens should be designed based on all these factors, as delineated below, while critically comparing the effects of radiommunotherapy to immunotherapy alone (as exemplified in the IMPORTANCE trial (NCT03386357) for the treatment of recurrent or metastatic HNSCC. 


\section{Refining radiotherapy modalities to maximize the therapeutic window of radioimmunotherapy.}

Revisiting doses and fractionation. For decades, RT doses and fractionations have been empirically set by clinicians with sole scope to achieve local tumor control. For multiple indications, such a conventional schedule corresponded to the delivery of 1.8-2 Gy per day, in 5 days per week, during 5-8 weeks. Clinical trials provided rationale for recommending different standard doses for specific tumors, including a total of 70 Gy for HNSCC, 66 Gy for NSCLC and 74-80 Gy for prostate cancer. ${ }^{17}$ More recently, the classical dose prescription paradigm has shifted toward higher doses per session and a protracted number of sessions, especially in cases in which RT is delivered to relatively small target volumes. Moreover, precision RT guided by 3D imaging has enabled the delivery of up to $20 \mathrm{~Gy}$ in one single dose, a regimen that can be routinely used to eradicate isolated brain metastases with minimal side effects. ${ }^{60}$

Based on these advances, attempts have been made to increase the RT dose up to a threshold dictated by toxicity on normal tissues, resembling prior attempts of 'dose intensification' for cytotoxic chemotherapies. ${ }^{61}$ However, such an approach, which is supported by a merely cancer cell-autonomous view of tumor biology, collides with the ever more accepted idea that any form of cancer therapy (conventional chemotherapy, targeted therapy, RT) must induce an anticancer immune response to yield a long-term response beyond treatment discontinuation. ${ }^{62}$

Supporting the notion that high RT doses not always enable systemic disease control, hypofractionated radiation ( 3 doses of 8 Gy each delivered in 3 consecutive days), but not a single dose of $20 \mathrm{~Gy}$, enables efficient abscopal responses in immunocompetent mice bearing syngeneic mammary carcinoma or colorectal carcinoma cells, when mice are simultaneously treated with a CTLA4-targeting ICB or with a monoclonal antibody neutralizing multiple TGF- 
$\beta$ isoforms. ${ }^{52,55,63}$ Abscopal responses driven by RT in the context of TGF- $\beta$ inhibition can be further boosted by the concomitant administration of a PD-1-targeting antibody, ultimately resulting in the generation of an in situ anticancer vaccine that enable long-term disease eradication coupled with protective immunological memory. ${ }^{52}$

Abscopal responses also rely on the dynamic recruitment and activation of immune cells into irradiated tumors. ${ }^{64,65}$ These include BATF3-dependent dendritic cells, whose recruitment requires the local secretion of type I IFN downstream of transmembrane protein 173 (TMEM173, best known as STING) activation. ${ }^{55,66}$ Hypofractionated RT favors the accumulation of endogenous DNA in the cytosol of irradiated cells, and hence efficiently drives STING signaling, a process that is inhibited when RT doses higher than a 10-12 Gy threshold (depending on cell type) are used as a consequence of the upregulation of the cytosolic nuclease three prime repair exonuclease 1 (TREX1). ${ }^{55}$ Importantly, cytosolic DNA accumulating in cancer cells responding to hypofractionated RT can be efficiently shuttled to dendritic cells via exosomes, and this further contributes to type I IFN production ${ }^{67}$. Clinical evidence in support of the notion that hypofractionated RT (5 fractions of 6 Gy each) in combination with ICBs targeting CTLA4 can generate robust abscopal responses is emerging. ${ }^{57}$

Along similar lines, it has recently been shown that low RT doses (a single dose of 2 Gy) efficiently boost the ability of CAR T cells to eliminate cancer cells that escaped conventional recognition by losing expression of the CAR target antigen. ${ }^{68}$ In this setting, low-dose RT appears to sensitize antigen-negative cancer cells to the lethal effects of TNF superfamily member 10 (TNFSF10; best known as TRAIL), which is produced by CAR T cells upon CARdependent activation but mediates TCR-independent effector functions. ${ }^{68}$ Supporting the clinical relevance of these findings, a patient with diffuse large-cell lymphoma receiving CD19targeting CAR T-cell therapy despite a large proportion of CD19- malignant cells exhibited systemic disease clearance 1 month after treatment, yet relapsed massively starting 2 months 
after treatment, with the only exception of the left thigh, which had received low-dose palliative RT (4 fractions of 5 Gy each) before CAR T-cell infusion and persisted disease-free up to 6 months after treatment. ${ }^{68}$

These findings comfort the idea that the optimal radiation dose required for radioimmunotherapy may be lower than the MTD, at least in some oncological indications. This insight offers the opportunity to define new therapeutic windows in which RT is administered at lower doses to minimize its toxicity and to maximize its efficacy due to synergistic combination with immunotherapy. These observations are also important for the response of normal tissue to RT. Indeed, even the most sophisticated irradiation plan inevitably involves the exposure of large volumes of normal tissues to low RT doses, causing immunomodulatory effects that are yet poorly defined.

Irradiation of smaller volumes. In addition to the total radiation dose, the volume of irradiated tissue has a major impact on the side effects of RT. Thus, even when high-dose RT is administered in a few sessions to a small volume, as typically achieved by brachytherapy and stereotactic RT, side effects remain relatively mild. These irradiation techniques offer indeed the advantage that the volume to which RT is delivered is sharply delimited, reducing collateral damage to adjacent organs including lymph nodes. ${ }^{69}$

Abscopal responses to RT (especially in the context of radioimmunotherapy) illustrate the possibility that anticancer immune responses elicited by RT can propagate outside of the radiation field. This raises the intriguing possibility that RT may elicit robust clinical responses also when parts of the (rather than the entire) tumor is irradiated. Preclinical and clinical evidence in support of this notion has begun to emerge. ${ }^{70,71}$ However, caution should be used 
when these findings are interpreted, as the areas of the tumor outside of the irradiation field also receive RT, albeit at lower doses, which may be responsible for, or at least contribute to, therapeutic efficacy. ${ }^{72}$ Moreover, in the case of radioimmunotherapy, responses outside of the irradiation field can simply originate from immunotherapy, especially in immunosensitive tumors. ${ }^{72}$ Adjuvant RT after breast conservation surgery constitutes a welcome alternative to mutilating mastectomy for breast cancer patients, because it not only decreases local relapse rates (as radical surgery does) but also diminishes the risk of distant relapse, ${ }^{73}$ pointing to the elicitation of an abscopal response targeting micrometastases. In this setting, accelerated partial breast irradiation (APBI) using multicatheter brachytherapy stands out as a morbidity-reducing alternative to whole breast irradiation for the treatment of low-risk mammary carcinoma, ${ }^{74}$ lending further support that larger irradiation volumes do not necessarily translate in improved disease control.

Sparing draining lymph nodes and the gut. Conventional RT regimens are generally conceived to deliver a full dose (50-70Gy) to the tumor and prophylactic coverage to tumordraining lymph nodes (TDLNs) (45-50 Gy), as established by multiple clinical trials in various indications (e.g., HNSCC, cervical cancer, NSCLC). This approach may not be particularly appropriate when RT is delivered in doses and fractionations that support the activation of anticancer immunity, and even less so in the context of radioimmunotherapy. Although TDLNs may not be the only sites of T-cell cross-priming by dendritic cells (which can also occur in intratumoral tertiary lymphoid structures) $)^{75}$ they constitute major platforms for the initiation of local and systemic antitumor immune responses. Accordingly, TDLNs increase in volume as a consequent of robust $\mathrm{CD} 8^{+} \mathrm{CTL}$ infiltration when transplantable mouse melanomas and breast carcinomas are exposed to hypofractionated RT in the context of PD-1 blockage. ${ }^{76}$ Thus, it may be detrimental to perturb TDLNs with RT. In support of this notion, nasopharyngeal carcinoma 
patients with tumor-free TDLNs and treated with TDLN-sparing IMRT exhibited rare locoregional relapse. ${ }^{77}$ Similarly, recent clinical data with partial tumor irradiation (which spares TDLNs) combined with pembrolizumab compare positively with previous results involving TDLN irradiation. ${ }^{71}$ However, these findings should be interpreted with caution, as multiple patients involved in the trial had tumors that are potentially sensitive to pembrolizumab alone. ${ }^{72}$ Clinical trials comparatively evaluating TLDN irradiation versus TDLN sparing in the context of radioimmunotherapy are urgently awaited. Of note, optimal therapeutic responses to RT and radioimmunotherapy may also be compromised, at least to some extent, by the irradiation of the small and large intestines. Indeed, bowel irradiation has been shown to alter the composition of the gut microbiota, ${ }^{78}$ which in turn impacts on the efficacy of multiple therapeutic regimens including immunotherapy. ${ }^{79}$

Optimizing radioimmunotherapy: sequencing. The recent demonstration that the adjuvant administration of PD-L1-targeting ICBs after chemoradiation postpones the onset of metastasis and improves the survival of patients with stage III NSCLC ${ }^{12}$ may transform the field of oncology. One fundamental question that arises from these results concerns the order in which different therapies should be administered, and if a concurrent administration of RT and immunotherapy would have yielded better results. Unlocking immunological checkpoints before or after, rather than concomitant to, radiotherapy may offer the potential to avoid potentially cumulative toxicities. This becomes even more relevant in light of the probable surge in dual or triple immunotherapies that, especially if combined with radiotherapy or chemoradiation, ${ }^{80}$ may demand sequential rather than simultaneous interventions to manage side effects. Unfortunately, clinical data robustly comparing different treatment sequencing are largely missing in the setting of radioimmunotherapy (Table 1). It can be speculated though that the increasing use of first-line immunotherapy will result in a situation where radiotherapy 
will often be performed after immunotherapy. That said, both existing data plead in favor of the administration of hypofractionated radiotherapy before PD-L1 blockade, ${ }^{12,81}$ perhaps because it stimulates tumor infiltration by T lymphocytes.${ }^{64}$ One clinical trial is currently open to define the optimal scheduling of PD-1 and CTLA4 blockade with respect to RT in patients with metastatic cancers (NCT03453892). In this setting, quantitative systems pharmacology models, which include key elements of immuno-oncology and dose-exposure-target modulation features, ${ }^{82}$ may assist the understanding of immune cell dynamics within irradiated tumors.

Optimizing radioimmunotherapy: biomarkers. A large panel of immunotherapies beyond ICBs have been developed, and will soon enter (or have already entered) clinical practice. These include oncolytic virotherapy, CAR T-cell therapy and a wide array of small molecules to functionally alter the tumor microenvironment toward a immunostimulatory configuration. ${ }^{14}$ In this setting, great efforts have been dedicated to the identification of reliable predictive biomarkers of response, reflecting not only safety issues, but also economic considerations ${ }^{83}$ It appears plausible that such biomarkers -be they based on the measurement of immunological parameters in the blood or in the tumor - will guide optimal radioimmunotherapy in the future, not only with respect to the choice of the best immunotherapeutic agent for combinatorial regimens, but also with regard to RT doses and schedule. The local upregulation of PD-L1 in response neoadjuvant chemoradiotherapy of rectal cancers is associated with favorable $\operatorname{prognosis}^{84}$ and might speculatively predict responsiveness to immunotherapy. Moreover, computational imaging (radiomics) stands out as a promising strategy to non-invasively quantify tumor infiltration by $\mathrm{CD}^{+} \mathrm{T}$ cells, ${ }^{85}$ which is an important positive prognostic factor for patients affected by multiple tumors. ${ }^{86}$ In particular, the ability of radiomics to provide a longitudinal, non-invasive monitoring of the tumor microenvironment may support the implementation of a personalized radioimmunotherapy, with the ultimate goal that each patient 
receives a treatment modality that triggers an effective anticancer immune response. Highdimensional single-cell analyses using genomics, transcriptomics, proteomics and metabolomics approaches are also on the verge of revolutionizing biomarker discovery and clinical practice. ${ }^{87}$ This technology might be used as an inclusion/exclusion criterion for clinical trials beyond the mere presence of $\mathrm{CD}^{+} \mathrm{T}$ cells (as in NCT03453892).

Current refinements in radioimmunotherapy trials offer the advantage to collect tumor biopsies after treatment. Such trials constitute a valuable source of samples for characterizing responses and resistance to radioimmunotherapy way beyond murine models. Indeed, standard treatment might per se affect the expression of immune-related biomarkers, which may prevent a careful prognostic assessment and/or misguide therapeutic decisions. For instance, rectal tumors exposed to pre-operative chemoradiation alone exhibit increased PD-L1 expression, ${ }^{84}$ which offers a strong rationale to combine treatment with adjuvant PD-1/PD-L1 blockage. Similar observations have been made in both the melanoma ${ }^{88}$ and HNSCC setting. ${ }^{89}$ Alterations in the peripheral blood compartment, including shifts in major $\mathrm{T}$ cell populations, may also offer a convenient, non-invasive gateway to monitor responses to RT and radioimmunotherapy in cancer patients. ${ }^{90}$ 


\section{Chemoradioimmunotherapy or radioimmunotherapy? Combination of cytotoxic}

chemotherapy with RT has demonstrated superiority over RT employed as a standalone intervention at enabling local disease control and sometimes improved organ preservation and survival in patients with multiple tumor types. ${ }^{91}$ However, such a therapeutic success often came with an excess in complications and side effects. ${ }^{92}$ An in-depth understanding of the tumor microenvironment and its influence on resistance to immunotherapy will be instrumental for defining potent radioimmunotherapy regimens that do not require the addition of cytotoxic chemotherapy for optimal efficacy. Preliminary clinical data from ongoing studies underscore the fact that PD-L1/PD-1 blockade combines safely with concurrent RT and cetuximab alone in HNSCC patients ${ }^{93,94}$, as well as with RT plus platinum-based chemotherapy in NSCLC patients ${ }^{95}$. However, robust demonstration of clinical benefits is still awaited. Similarly, while recent evidence suggests that adjuvant PD-L1 blockade improves disease outcome after chemoradiation in NSCLC patients, ${ }^{12}$ the vast majority of preclinical evidence supporting the implementation of concurrent radioimmunotherapy in the clinics do not involve cytotoxic chemotherapy, ${ }^{11,51,53,55,63}$ suggesting that immunotherapy might per se combine favorably with RT. Thus, conventional chemotherapeutics may no longer be required to achieve robust clinical responses in the context of radioimmunotherapy, which may also translate in decreased incidence and severity of side effects. Clinical trials should specifically be designed to investigate this possibility. For instance, it might be investigated whether the superior efficacy of PD-1 blockade plus chemoradiotherapy against NSCLC (Ref. ${ }^{12}$ ). truly requires chemotherapy to be included in the therapeutic protocol.

Numerous ongoing trials are designed to induce abscopal responses. Although data are not mature yet, preliminary findings are promising. Combining PD-1/PD-L1 blockade with RT has been associated with durable out-of-field responses in 3/9 (33\%) evaluable patients with metastatic triple negative breast cancer unselected for PD-L1 expression. ${ }^{96}$ PD-1 blockade 
preceded by SBRT resulted in a 2-fold increase in ORR without accrued toxicity in NSCLC patients. ${ }^{97}$ In sharp contrast, addition of SBRT to PD-1 blockade in patients with metastatic HNSCC was safe but failed to improve outcome in a randomized evaluation of abscopal responses. ${ }^{98}$ A randomized Phase II trial testing PD-1 blockade plus RT in patients HNSCC (IMPORTANCE, Keynote-717) comparatively evaluates standalone PD-1 targeting immunotherapy to radioimmunotherapy. The results of this study will provide useful insights into the relative contribution of radiotherapy to clinical responses to immunotherapy.

Radioimmunotherapy beyond conventional X-rays. Data have been generated in support of the notion that very low irradiation doses - in the range of conventional full body CT scans can mediate robust immunostimulatory effects that may combine favorably with immunotherapy. ${ }^{99}$ Densely ionizing particles (protons, carbon ions), which are characterized by a dose deposit in a narrow depth range (leading to minimal exit dose), are being used in an increasing number of indications, with the highest benefit probably being for pediatric patients linked to reductions in both dose-dependent complications and risk for secondary tumors. ${ }^{100}$ Protons and carbon ions are generally considered superior to photons (conventional X-rays) for distribution ballistics. ${ }^{101}$ Moreover, carbon ions may provide increased biological and clinical effectiveness, at least in specific indications that are generally refractory to conventional RT, such as bone and soft tissue sarcomas of the skull base. ${ }^{102}$ Preliminary data suggest that protons resemble photons in their immunological effects. ${ }^{103}$ Taken together, these observations suggest that the superior dose distribution offered by protons, which spare a considerably higher amount of normal tissues than photons, provides a good opportunity for radioimmunotherapy combinations. However, whether protons and carbon ions can be favorably combined with immunotherapy remains to be demonstrated. 


\section{Concluding remarks}

RT has been used for more than a century for the clinical management of virtually all cancers with often positive results, both in terms of side effects and efficacy. Such a favorable therapeutic window places RT in a privileged position for the development of combinatorial treatment regimens. In line with this notion, the delivery of RT along with cytotoxic chemotherapy has enables improved local disease control in multiple oncological indications, in some cases accompanied by superior organ preservation and patient survival. ${ }^{104}$ However, chemoradiation protocols are often associated with increased incidence and severity of side effects, reflecting the fact that both RT and chemotherapy are often used at (or near to) their MTD. ${ }^{105}$ It can be anticipated that low-dose molecular targeted radiotherapy using radiolabeled molecules will overcome the problem of toxicity. ${ }^{106,107}$ Over the past decade, immunotherapy has largely transformed the management of multiple solid tumors. ${ }^{14}$ However, response rates to immunotherapy employed as single therapeutic interventions often are low (with the exception of CAR T-cell therapy, which is associated with response rates $>80 \%$ for selected indications), calling for the development of combinatorial regimens. In this context, RT stands out as an optimal partner for immunotherapy. However, conventional RT regimens will have to be redesigned for radioimmunotherapy to mediate superior efficacy in the presence of limited side effects (Figure 2). Revisiting doses and fractionation schedules, reducing delivery volumes, sparing both TDLNs and the intestine, limiting the concomitant administration of cytotoxic chemotherapeutics, employing radiomics to longitudinally monitor responses, and elucidating the actual therapeutic value of protons and carbon ions are some of the directions that will foster the development of safe and efficient radioimmunotherapy regimens to treat cancer.

Acknowledgements. ED is supported by Agence National de la Recherche (ANR); Association pour la recherche sur le cancer (ARC), Institut National du Cancer (INCa) [\#INCa-DGOS-Inserm_12551], and Fondation pour la Recherche Médicale (FRM). LG is supported by a Breakthrough Level 2 grant from the US Department of Defense 
(DoD), Breast Cancer Research Program (BRCP) [\#BC180476P1], by a startup grant from the Dept. of Radiation Oncology at Weill Cornell Medicine (New York, US), by industrial collaborations with Lytix (Oslo, Norway) and Phosplatin (New York, US), and by donations from Phosplatin (New York, US), the Luke Heller TECPR2 Foundation (Boston, US) and Sotio a.s. (Prague, Czech Republic). GK is supported by the Ligue contre le Cancer (équipe labellisée); Agence National de la Recherche (ANR) - Projets blancs; ANR under the frame of E-Rare-2, the ERA-Net for Research on Rare Diseases; Association pour la recherche sur le cancer (ARC); Cancéropôle Ilede-France; Chancelerie des universités de Paris (Legs Poix), Fondation pour la Recherche Médicale (FRM); a donation by Elior; the European Commission (ArtForce); European Research Area Network on Cardiovascular Diseases (ERA-CVD, MINOTAUR); the European Research Council (ERC); Fondation Carrefour; Institut National du Cancer (INCa); Inserm (HTE); Institut Universitaire de France; LeDucq Foundation; the LabEx Immuno-Oncology; the RHU Torino Lumière; the Seerave Foundation; the SIRIC Stratified Oncology Cell DNA Repair and Tumor Immune Elimination (SOCRATE); and the SIRIC Cancer Research and Personalized Medicine (CARPEM).

Author Contributions. ED, LG and GK conceived the article. ED and CC prepared the first version of the manuscript and display items with inputs and revisions from LG and GK. LG and GK addressed comments from reviewers. All authors approved the final version of the article.

Search Strategy and Selection Criteria. PubMed was queried for the string "radiation and immunotherapy" for articles published after 2010 and entries were manually selected for relevance. Additional articles published both before and after 2010 were manually selected for inclusion by the authors. 


\section{Legends to Figures}

Figure 1. Radioimmunotherapy strategies to tackle oligometastatic disease, impact on therapeutic benefits. The therapeutic effects expected from integrating radiotherapy and systemic immunotherapy may vary according to radiotherapy modalities (dose, fractionation, irradiated volume), as well as study design. As it stands, combining focal radiotherapy to one or a few sites with systemic immunomodulation (a) stands out as a promising approach as compared to debulking strategies based on radiotherapy alone (b), or to combinatorial approaches involving the systematic irradiation of all disease sites (c). *In the PACIFIC trial, immunotherapy improved the outcome of non-metastatic patients who had all their macroscopic tumor sites previously irradiated. ${ }^{20}$

Figure 2. From conventional chemoradiation to radioimmunotherapy. Improving therapeutic index in the era of radioimmunotherapy requires the redefinition of multiple approaches established in the context of conventional chemoradiation, including (but not limited to) doses, fractionation schedules, as well as irradiation volumes and targets. Clinical trials designed to investigate novel radioimmunotherapy approach should be specifically designed to simultaneously achieve limited toxicity to normal tissues and superior systemic disease control. 


\section{References}

1. Jaffray DA. Image-guided radiotherapy: from current concept to future perspectives. Nature reviews Clinical oncology 2012; 9(12): 688-99.

2. Kuban DA, Tucker SL, Dong L, et al. Long-term results of the M. D. Anderson randomized dose-escalation trial for prostate cancer. Int J Radiat Oncol Biol Phys 2008; 70(1): 67-74.

3. Strnad V, Ott OJ, Hildebrandt G, et al. 5-year results of accelerated partial breast irradiation using sole interstitial multicatheter brachytherapy versus whole-breast irradiation with boost after breast-conserving surgery for low-risk invasive and in-situ carcinoma of the female breast: a randomised, phase 3, non-inferiority trial. Lancet 2016; 387(10015): 229-38.

4. Yamamoto M, Serizawa T, Shuto T, et al. Stereotactic radiosurgery for patients with multiple brain metastases (JLGK0901): a multi-institutional prospective observational study. Lancet Oncol 2014; 15(4): 387-95.

5. Mukesh MB, Barnett GC, Wilkinson JS, et al. Randomized controlled trial of intensitymodulated radiotherapy for early breast cancer: 5-year results confirm superior overall cosmesis. J Clin Oncol 2013; 31(36): 4488-95.

6. Nutting CM, Morden JP, Harrington KJ, et al. Parotid-sparing intensity modulated versus conventional radiotherapy in head and neck cancer (PARSPORT): a phase 3 multicentre randomised controlled trial. Lancet Oncol 2011; 12(2): 127-36.

7. Chargari C, Soria JC, Deutsch E. Controversies and challenges regarding the impact of radiation therapy on survival. Ann Oncol 2013; 24(1): 38-46.

8. Bradley JD, Paulus R, Komaki R, et al. Standard-dose versus high-dose conformal radiotherapy with concurrent and consolidation carboplatin plus paclitaxel with or without cetuximab for patients with stage IIIA or IIIB non-small-cell lung cancer (RTOG 0617): a randomised, two-by-two factorial phase 3 study. Lancet Oncol 2015; 16(2): 187 99. 
9. Gilbert MR, Dignam JJ, Armstrong TS, et al. A randomized trial of bevacizumab for newly diagnosed glioblastoma. N Engl J Med 2014; 370(8): 699-708.

10. Gillison ML, Trotti AM, Harris J, et al. Radiotherapy plus cetuximab or cisplatin in human papillomavirus-positive oropharyngeal cancer (NRG Oncology RTOG 1016): a randomised, multicentre, non-inferiority trial. Lancet 2018.

11. Demaria $\mathrm{S}, \mathrm{Ng} \mathrm{B}$, Devitt $\mathrm{ML}$, et al. Ionizing radiation inhibition of distant untreated tumors (abscopal effect) is immune mediated. Int J Radiat Oncol Biol Phys 2004; 58(3): 862-70.

12. Antonia SJ, Villegas A, Daniel D, et al. Overall Survival with Durvalumab after Chemoradiotherapy in Stage III NSCLC. N Engl J Med 2018.

13. Louvel G, Bahleda R, Ammari S, et al. Immunotherapy and pulmonary toxicities: can concomitant immune-checkpoint inhibitors with radiotherapy increase the risk of radiation pneumonitis? Eur Respir J 2018; 51(1).

14. Galluzzi L, Chan TA, Kroemer G, Wolchok JD, Lopez-Soto A. The hallmarks of successful anticancer immunotherapy. Sci Transl Med 2018; 10(459).

15. Buque A, Galluzzi L. Modeling Tumor Immunology and Immunotherapy in Mice. Trends Cancer 2018; 4(9): 599-601.

16. Dewey WC, Miller HH, Leeper DB. Chromosomal aberrations and mortality of xirradiated mammalian cells: emphasis on repair. Proc Natl Acad Sci U S A 1971; 68(3): 667-71.

17. Yamoah K, Showalter TN, Ohri N. Radiation Therapy Intensification for Solid Tumors: A Systematic Review of Randomized Trials. Int J Radiat Oncol Biol Phys 2015; 93(4): 737-45.

18. Vanpouille-Box C, Formenti SC, Demaria S. Toward Precision Radiotherapy for Use with Immune Checkpoint Blockers. Clin Cancer Res 2018; 24(2): 259-65.

19. Ko EC, Benjamin KT, Formenti SC. Generating antitumor immunity by targeted radiation therapy: Role of dose and fractionation. Adv Radiat Oncol 2018; 3(4): 486-93. 
20. Moding EJ, Kastan MB, Kirsch DG. Strategies for optimizing the response of cancer and normal tissues to radiation. Nat Rev Drug Discov 2013; 12(7): 526-42.

21. Leibowitz BJ, Wei L, Zhang L, et al. Ionizing irradiation induces acute haematopoietic syndrome and gastrointestinal syndrome independently in mice. Nat Commun 2014; 5: 3494.

22. Straub JM, New J, Hamilton CD, Lominska C, Shnayder Y, Thomas SM. Radiationinduced fibrosis: mechanisms and implications for therapy. J Cancer Res Clin Oncol 2015; 141(11): 1985-94.

23. Kainthola A, Haritwal T, Tiwari M, et al. Immunological Aspect of Radiation-Induced Pneumonitis, Current Treatment Strategies, and Future Prospects. Front Immunol 2017; 8: 506.

24. Hallahan DE, Geng L, Shyr Y. Effects of intercellular adhesion molecule 1 (ICAM-1) null mutation on radiation-induced pulmonary fibrosis and respiratory insufficiency in mice. J Natl Cancer Inst 2002; 94(10): 733-41.

25. Meziani L, Mondini M, Petit B, et al. CSF1R inhibition prevents radiation pulmonary fibrosis by depletion of interstitial macrophages. Eur Respir J 2018; 51(3).

26. McBride WH, Vegesna V. Role of the thymus in radiation-induced lung damage after bone marrow transplantation. Radiat Res 1997; 147(4): 501-5.

27. Jones KI, Tiersma J, Yuzhalin AE, et al. Radiation combined with macrophage depletion promotes adaptive immunity and potentiates checkpoint blockade. EMBO Mol Med 2018; 10(12).

28. Wunderlich R, Ernst A, Rodel F, et al. Low and moderate doses of ionizing radiation up to 2 Gy modulate transmigration and chemotaxis of activated macrophages, provoke an anti-inflammatory cytokine milieu, but do not impact upon viability and phagocytic function. Clin Exp Immunol 2015; 179(1): 50-61.

29. Meng XM, Nikolic-Paterson DJ, Lan HY. TGF-beta: the master regulator of fibrosis. Nat Rev Nephrol 2016; 12(6): 325-38. 
30. Mariathasan S, Turley SJ, Nickles D, et al. TGFbeta attenuates tumour response to PDL1 blockade by contributing to exclusion of T cells. Nature 2018; 554(7693): 544-8.

31. Bouquet F, Pal A, Pilones KA, et al. TGFbeta1 inhibition increases the radiosensitivity of breast cancer cells in vitro and promotes tumor control by radiation in vivo. Clin Cancer Res 2011; 17(21): 6754-65.

32. Flechsig P, Dadrich M, Bickelhaupt S, et al. LY2109761 attenuates radiation-induced pulmonary murine fibrosis via reversal of TGF-beta and BMP-associated proinflammatory and proangiogenic signals. Clin Cancer Res 2012; 18(13): 3616-27.

33. Formenti SC, Lee P, Adams S, et al. Focal Irradiation and Systemic TGFbeta Blockade in Metastatic Breast Cancer. Clin Cancer Res 2018; 24(11): 2493-504.

34. Principe DR, Doll JA, Bauer J, et al. TGF-beta: duality of function between tumor prevention and carcinogenesis. J Natl Cancer Inst 2014; 106(2): djt369.

35. Galluzzi L, Buque A, Kepp O, Zitvogel L, Kroemer G. Immunogenic cell death in cancer and infectious disease. Nat Rev Immunol 2017; 17(2): 97-111.

36. Nefla M, Holzinger D, Berenbaum F, Jacques C. The danger from within: alarmins in arthritis. Nat Rev Rheumatol 2016; 12(11): 669-83.

37. Bangert A, Andrassy M, Muller AM, et al. Critical role of RAGE and HMGB1 in inflammatory heart disease. Proc Natl Acad Sci U S A 2016; 113(2): E155-64.

38. Ryu C, Sun H, Gulati M, et al. Extracellular Mitochondrial DNA Is Generated by Fibroblasts and Predicts Death in Idiopathic Pulmonary Fibrosis. American journal of respiratory and critical care medicine 2017; 196(12): 1571-81.

39. Fox J, Haston CK. CXC receptor 1 and 2 and neutrophil elastase inhibitors alter radiationinduced lung disease in the mouse. Int J Radiat Oncol Biol Phys 2013; 85(1): 215-22.

40. Burdelya LG, Gleiberman AS, Toshkov I, et al. Toll-like receptor 5 agonist protects mice from dermatitis and oral mucositis caused by local radiation: implications for head-andneck cancer radiotherapy. Int J Radiat Oncol Biol Phys 2012; 83(1): 228-34. 
41. Galluzzi L, Yamazaki T, Kroemer G. Linking cellular stress responses to systemic homeostasis. Nat Rev Mol Cell Biol 2018; 19(11): 731-45.

42. Johnston CJ, Manning C, Hernady E, et al. Effect of total body irradiation on late lung effects: hidden dangers. Int J Radiat Biol 2011; 87(8): 902-13.

43. Wirsdorfer F, Cappuccini F, Niazman M, et al. Thorax irradiation triggers a local and systemic accumulation of immunosuppressive CD4+ FoxP3+ regulatory T cells. Radiat Oncol 2014; 9: 98.

44. Weng L, Williams RO, Vieira PL, Screaton G, Feldmann M, Dazzi F. The therapeutic activity of low-dose irradiation on experimental arthritis depends on the induction of endogenous regulatory T cell activity. Ann Rheum Dis 2010; 69(8): 1519-26.

45. Price JG, Idoyaga J, Salmon H, et al. CDKN1A regulates Langerhans cell survival and promotes Treg cell generation upon exposure to ionizing irradiation. Nat Immunol 2015; 16(10): 1060-8.

46. Waer M, Ang KK, Van der Schueren E, Vandeputte M. Influence of radiation field and fractionation schedule of total lymphoid irradiation (TLI) on the induction of suppressor cells and stable chimerism after bone marrow transplantation in mice. J Immunol 1984; 132(2): 985-90.

47. Kachikwu EL, Iwamoto KS, Liao YP, et al. Radiation enhances regulatory $\mathrm{T}$ cell representation. Int J Radiat Oncol Biol Phys 2011; 81(4): 1128-35.

48. Kumar S, Singh RK, Meena R. Emerging targets for radioprotection and radiosensitization in radiotherapy. Tumour Biol 2016; 37(9): 11589-609.

49. Kepp O, Senovilla L, Vitale I, et al. Consensus guidelines for the detection of immunogenic cell death. Oncoimmunology 2014; 3(9): e955691.

50. Vanpouille-Box C, Demaria S, Formenti SC, Galluzzi L. Cytosolic DNA Sensing in Organismal Tumor Control. Cancer Cell 2018; 34(3): 361-78.

51. Dovedi SJ, Cheadle EJ, Popple AL, et al. Fractionated Radiation Therapy Stimulates Antitumor Immunity Mediated by Both Resident and Infiltrating Polyclonal T-cell 
Populations when Combined with PD-1 Blockade. Clin Cancer Res 2017; 23(18): 551426.

52. Vanpouille-Box C, Diamond JM, Pilones KA, et al. TGFbeta Is a Master Regulator of Radiation Therapy-Induced Antitumor Immunity. Cancer Res 2015; 75(11): 2232-42.

53. Deng L, Liang H, Burnette B, et al. Irradiation and anti-PD-L1 treatment synergistically promote antitumor immunity in mice. J Clin Invest 2014; 124(2): 687-95.

54. Ngwa W, Irabor OC, Schoenfeld JD, Hesser J, Demaria S, Formenti SC. Using immunotherapy to boost the abscopal effect. Nat Rev Cancer 2018; 18(5): 313-22.

55. Vanpouille-Box C, Alard A, Aryankalayil MJ, et al. DNA exonuclease Trex1 regulates radiotherapy-induced tumour immunogenicity. Nat Commun 2017; 8: 15618.

56. Golden EB, Chhabra A, Chachoua A, et al. Local radiotherapy and granulocytemacrophage colony-stimulating factor to generate abscopal responses in patients with metastatic solid tumours: a proof-of-principle trial. Lancet Oncol 2015; 16(7): 795-803.

57. Formenti SC, Rudqvist NP, Golden E, et al. Radiotherapy induces responses of lung cancer to CTLA-4 blockade. Nat Med 2018.

58. Klug F, Prakash H, Huber PE, et al. Low-dose irradiation programs macrophage differentiation to an iNOS(+)/M1 phenotype that orchestrates effective $\mathrm{T}$ cell immunotherapy. Cancer Cell 2013; 24(5): 589-602.

59. Paris F, Fuks Z, Kang A, et al. Endothelial apoptosis as the primary lesion initiating intestinal radiation damage in mice. Science 2001; 293(5528): 293-7.

60. Kocher M, Wittig A, Piroth MD, et al. Stereotactic radiosurgery for treatment of brain metastases. A report of the DEGRO Working Group on Stereotactic Radiotherapy. Strahlenther Onkol 2014; 190(6): 521-32.

61. Landau DB, Hughes L, Baker A, et al. IDEAL-CRT: A Phase 1/2 Trial of Isotoxic DoseEscalated Radiation Therapy and Concurrent Chemotherapy in Patients With Stage II/III Non-Small Cell Lung Cancer. Int J Radiat Oncol Biol Phys 2016; 95(5): 1367-77. 
62. Galluzzi L, Buque A, Kepp O, Zitvogel L, Kroemer G. Immunological Effects of Conventional Chemotherapy and Targeted Anticancer Agents. Cancer Cell 2015; 28(6): 690-714.

63. Dewan MZ, Galloway AE, Kawashima N, et al. Fractionated but not single-dose radiotherapy induces an immune-mediated abscopal effect when combined with antiCTLA-4 antibody. Clin Cancer Res 2009; 15(17): 5379-88.

64. Frey B, Ruckert M, Weber J, et al. Hypofractionated Irradiation Has Immune Stimulatory Potential and Induces a Timely Restricted Infiltration of Immune Cells in Colon Cancer Tumors. Front Immunol 2017; 8: 231.

65. Hettich M, Lahoti J, Prasad S, Niedermann G. Checkpoint Antibodies but not T CellRecruiting Diabodies Effectively Synergize with TIL-Inducing gamma-Irradiation. Cancer Res 2016; 76(16): 4673-83.

66. Fuertes MB, Kacha AK, Kline J, et al. Host type I IFN signals are required for antitumor CD8+ T cell responses through CD8 $\{$ alpha $\}+$ dendritic cells. The Journal of experimental medicine 2011; 208(10): 2005-16.

67. Diamond JM, Vanpouille-Box C, Spada S, et al. Exosomes Shuttle TREX1-Sensitive IFN-Stimulatory dsDNA from Irradiated Cancer Cells to DCs. Cancer Immunol Res 2018; 6(8): 910-20.

68. DeSelm C, Palomba ML, Yahalom J, et al. Low-Dose Radiation Conditioning Enables CAR T Cells to Mitigate Antigen Escape. Mol Ther 2018; 26(11): 2542-52.

69. Grills IS, Mangona VS, Welsh R, et al. Outcomes after stereotactic lung radiotherapy or wedge resection for stage I non-small-cell lung cancer. J Clin Oncol 2010; 28(6): 928-35.

70. Markovsky E, Budhu S, Samstein RM, et al. An Anti-Tumor Immune Response is Evoked By Partial-Volume Single Dose Radiation in Two Murine Models. Int J Radiat Oncol Biol Phys 2018.

71. Luke JJ, Lemons JM, Karrison TG, et al. Safety and Clinical Activity of Pembrolizumab and Multisite Stereotactic Body Radiotherapy in Patients With Advanced Solid Tumors. J Clin Oncol 2018; 36(16): 1611-8. 
72. Formenti SC, Demaria S. Understanding Responses to Stereotactic Body Radiotherapy and Pembrolizumab. J Clin Oncol 2018; 36(25): 2661-2.

73. Overgaard M, Hansen PS, Overgaard J, et al. Postoperative radiotherapy in high-risk premenopausal women with breast cancer who receive adjuvant chemotherapy. Danish Breast Cancer Cooperative Group 82b Trial. N Engl J Med 1997; 337(14): 949-55.

74. Schafer R, Strnad V, Polgar C, et al. Quality-of-life results for accelerated partial breast irradiation with interstitial brachytherapy versus whole-breast irradiation in early breast cancer after breast-conserving surgery (GEC-ESTRO): 5-year results of a randomised, phase 3 trial. Lancet Oncol 2018; 19(6): 834-44.

75. Ma Y, Adjemian S, Mattarollo SR, et al. Anticancer chemotherapy-induced intratumoral recruitment and differentiation of antigen-presenting cells. Immunity 2013; 38(4): 72941.

76. Zhang X, Niedermann G. Abscopal Effects With Hypofractionated Schedules Extending Into the Effector Phase of the Tumor-Specific T-Cell Response. Int J Radiat Oncol Biol Phys 2018; 101(1): 63-73.

77. Chen J, Ou D, He X, Hu C. Sparing level Ib lymph nodes by intensity-modulated radiotherapy in the treatment of nasopharyngeal carcinoma. International journal of clinical oncology 2014; 19(6): 998-1004.

78. Muls A, Andreyev J, Lalondrelle S, Taylor A, Norton C, Hart A. Systematic Review: The Impact of Cancer Treatment on the Gut and Vaginal Microbiome in Women With a Gynecological Malignancy. Int J Gynecol Cancer 2017; 27(7): 1550-9.

79. Routy B, Le Chatelier E, Derosa L, et al. Gut microbiome influences efficacy of PD-1based immunotherapy against epithelial tumors. Science 2018; 359(6371): 91-7.

80. Twyman-Saint Victor C, Rech AJ, Maity A, et al. Radiation and dual checkpoint blockade activate non-redundant immune mechanisms in cancer. Nature 2015; 520(7547): 373-7.

81. Dovedi SJ, Adlard AL, Lipowska-Bhalla G, et al. Acquired resistance to fractionated radiotherapy can be overcome by concurrent PD-L1 blockade. Cancer Res 2014; 74(19): 5458-68. 
82. Kosinsky Y, Dovedi SJ, Peskov K, et al. Radiation and PD-(L)1 treatment combinations: immune response and dose optimization via a predictive systems model. J Immunother Cancer 2018; 6(1): 17.

83. Nishino M, Ramaiya NH, Hatabu H, Hodi FS. Monitoring immune-checkpoint blockade: response evaluation and biomarker development. Nature reviews Clinical oncology 2017; 14(11): 655-68.

84. Hecht M, Buttner-Herold M, Erlenbach-Wunsch K, et al. PD-L1 is upregulated by radiochemotherapy in rectal adenocarcinoma patients and associated with a favourable prognosis. Eur J Cancer 2016; 65: 52-60.

85. Sun R, Limkin EJ, Vakalopoulou M, et al. A radiomics approach to assess tumourinfiltrating CD8 cells and response to anti-PD-1 or anti-PD-L1 immunotherapy: an imaging biomarker, retrospective multicohort study. Lancet Oncol 2018; 19(9): 1180-91.

86. Fridman WH, Zitvogel L, Sautes-Fridman C, Kroemer G. The immune contexture in cancer prognosis and treatment. Nature reviews Clinical oncology 2017; 14(12): 717-34.

87. Krieg C, Nowicka M, Guglietta S, et al. High-dimensional single-cell analysis predicts response to anti-PD-1 immunotherapy. Nat Med 2018; 24(2): 144-53.

88. Derer A, Spiljar M, Baumler M, et al. Chemoradiation Increases PD-L1 Expression in Certain Melanoma and Glioblastoma Cells. Front Immunol 2016; 7: 610.

89. Ock CY, Kim S, Keam B, et al. Changes in programmed death-ligand 1 expression during cisplatin treatment in patients with head and neck squamous cell carcinoma. Oncotarget 2017; 8(58): 97920-7.

90. Evans JD, Morris LK, Zhang H, et al. Prospective Immunophenotyping of CD8(+) T Cells and Associated Clinical Outcomes of Patients With Oligometastatic Prostate Cancer Treated With Metastasis-Directed SBRT. Int J Radiat Oncol Biol Phys 2019; 103(1): 22940.

91. Uppaluri R, Zolkind P, Lin T, et al. Neoadjuvant pembrolizumab in surgically resectable, locally advanced HPV negative head and neck squamous cell carcinoma (HNSCC). Journal of Clinical Oncology 2017; 35(15_suppl): 6012-. 
92. Bernier J, Hall EJ, Giaccia A. Radiation oncology: a century of achievements. Nat Rev Cancer 2004; 4(9): 737-47.

93. Sun XS, Sire C, Tao Y, et al. A phase II randomized trial of pembrolizumab versus cetuximab, concomitant with radiotherapy (RT) in locally advanced (LA) squamous cell carcinoma of the head and neck (SCCHN): First results of the GORTEC 2015-01 “PembroRad" trial. Journal of Clinical Oncology 2018; 36(15_suppl): 6018-.

94. Tao Y, Auperin A, Sun XS, et al. Avelumab-cetuximab-radiotherapy (RT) versus standards of care (SoC) in locally advanced squamous cell carcinoma of the head and neck (SCCHN): Safety phase of the randomized trial GORTEC 2017-01 (REACH). Journal of Clinical Oncology 2018; 36(15_suppl): 6076-.

95. Peters S, Ruysscher DD, Dafni U, et al. Safety evaluation of nivolumab added concurrently to radiotherapy in a standard first line chemo-RT regimen in unresectable locally advanced NSCLC: The ETOP NICOLAS phase II trial. Journal of Clinical Oncology 2018; 36(15_suppl): 8510-.

96. McArthur HL, Barker CA, Gucalp A, et al. A phase II, single arm study assessing the efficacy of pembrolizumab (Pembro) plus radiotherapy (RT) in metastatic triple negative breast cancer (mTNBC). Journal of Clinical Oncology 2018; 36(15_suppl): 1017-.

97. Theelen W, H.Peulen@Nki.N1 NF, Lalezari F, et al. Randomized phase II study of pembrolizumab after stereotactic body radiotherapy (SBRT) versus pembrolizumab alone in patients with advanced non-small cell lung cancer: The PEMBRO-RT study. Journal of Clinical Oncology 2018; 36(15_suppl): 9023-.

98. McBride SM, Sherman EJ, Tsai CJ, et al. A phase II randomized trial of nivolumab with stereotactic body radiotherapy (SBRT) versus nivolumab alone in metastatic (M1) head and neck squamous cell carcinoma (HNSCC). Journal of Clinical Oncology 2018; 36(15_suppl): 6009-.

99. Rodrigues-Moreira S, Moreno SG, Ghinatti G, et al. Low-Dose Irradiation Promotes Persistent Oxidative Stress and Decreases Self-Renewal in Hematopoietic Stem Cells. Cell Rep 2017; 20(13): 3199-211. 
100. Yock TI, Yeap BY, Ebb DH, et al. Long-term toxic effects of proton radiotherapy for paediatric medulloblastoma: a phase 2 single-arm study. Lancet Oncol 2016; 17(3): 28798.

101. Lomax AJ, Bortfeld T, Goitein G, et al. A treatment planning inter-comparison of proton and intensity modulated photon radiotherapy. Radiother Oncol 1999; 51(3): 257-71.

102. Kamada T, Tsujii H, Blakely EA, et al. Carbon ion radiotherapy in Japan: an assessment of 20 years of clinical experience. Lancet Oncol 2015; 16(2): e93-e100.

103. Gameiro SR, Malamas AS, Bernstein MB, et al. Tumor Cells Surviving Exposure to Proton or Photon Radiation Share a Common Immunogenic Modulation Signature, Rendering Them More Sensitive to T Cell-Mediated Killing. Int J Radiat Oncol Biol Phys 2016; 95(1): 120-30.

104. Baumann M, Krause M, Overgaard J, et al. Radiation oncology in the era of precision medicine. Nat Rev Cancer 2016; 16(4): 234-49.

105. Hallqvist A, Bergstrom S, Bjorkestrand H, et al. Dose escalation to 84 Gy with concurrent chemotherapy in stage III NSCLC appears excessively toxic: Results from a prematurely terminated randomized phase II trial. Lung Cancer 2018; 122: 180-6.

106. Heskamp S, Hernandez R, Molkenboer-Kuenen JDM, et al. alpha- Versus beta-Emitting Radionuclides for Pretargeted Radioimmunotherapy of Carcinoembryonic AntigenExpressing Human Colon Cancer Xenografts. Journal of nuclear medicine : official publication, Society of Nuclear Medicine 2017; 58(6): 926-33.

107. Cheal SM, Xu H, Guo HF, et al. Theranostic pretargeted radioimmunotherapy of internalizing solid tumor antigens in human tumor xenografts in mice: Curative treatment of HER2-positive breast carcinoma. Theranostics 2018; 8(18): 5106-25.

108. Levy A, Massard C, Soria JC, Deutsch E. Concurrent irradiation with the antiprogrammed cell death ligand-1 immune checkpoint blocker durvalumab: Single centre subset analysis from a phase 1/2 trial. Eur J Cancer 2016; 68: 156-62. 
109. Tang C, Welsh JW, de Groot P, et al. Ipilimumab with Stereotactic Ablative Radiation Therapy: Phase I Results and Immunologic Correlates from Peripheral T Cells. Clin Cancer Res 2017; 23(6): 1388-96.

110. Williams NL, Wuthrick EJ, Kim H, et al. Phase 1 Study of Ipilimumab Combined With Whole Brain Radiation Therapy or Radiosurgery for Melanoma Patients With Brain Metastases. Int J Radiat Oncol Biol Phys 2017; 99(1): 22-30.

111. Kwon ED, Drake CG, Scher HI, et al. Ipilimumab versus placebo after radiotherapy in patients with metastatic castration-resistant prostate cancer that had progressed after docetaxel chemotherapy (CA184-043): a multicentre, randomised, double-blind, phase 3 trial. Lancet Oncol 2014; 15(7): 700-12.

112. Hiniker SM, Reddy SA, Maecker HT, et al. A Prospective Clinical Trial Combining Radiation Therapy With Systemic Immunotherapy in Metastatic Melanoma. Int J Radiat Oncol Biol Phys 2016; 96(3): 578-88.

113. Slovin SF, Higano CS, Hamid O, et al. Ipilimumab alone or in combination with radiotherapy in metastatic castration-resistant prostate cancer: results from an open-label, multicenter phase I/II study. Ann Oncol 2013; 24(7): 1813-21.

114. Seung SK, Curti BD, Crittenden M, et al. Phase 1 study of stereotactic body radiotherapy and interleukin-2--tumor and immunological responses. Sci Transl Med 2012; 4(137): $137 \mathrm{ra} 74$.

115. Bloch O, Lim M, Sughrue ME, et al. Autologous Heat Shock Protein Peptide Vaccination for Newly Diagnosed Glioblastoma: Impact of Peripheral PD-L1 Expression on Response to Therapy. Clin Cancer Res 2017; 23(14): 3575-84. 
Combinatorial immunoradiotherapy approaches

to tackle the oligometastatic disease, impact on therapeutic ratio

\begin{tabular}{l} 
Strategy \\
\hline Immunotherapy \\
Radiotherapy \\
1/ Sites \\
$2 /$ volumes \\
$3 /$ dose \\
Clinical demonstration \\
Therapeutic ratio \\
\hline
\end{tabular}
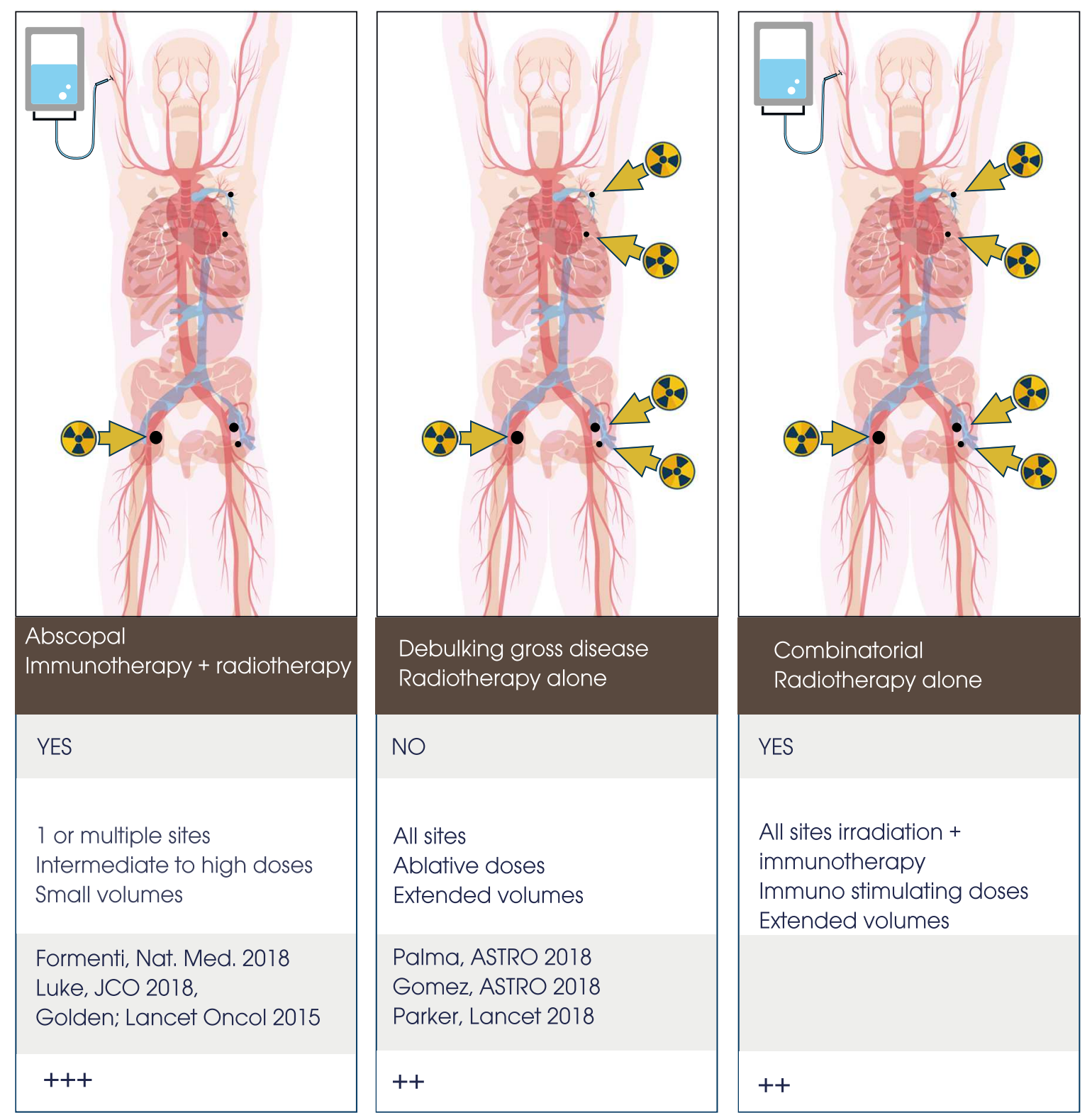


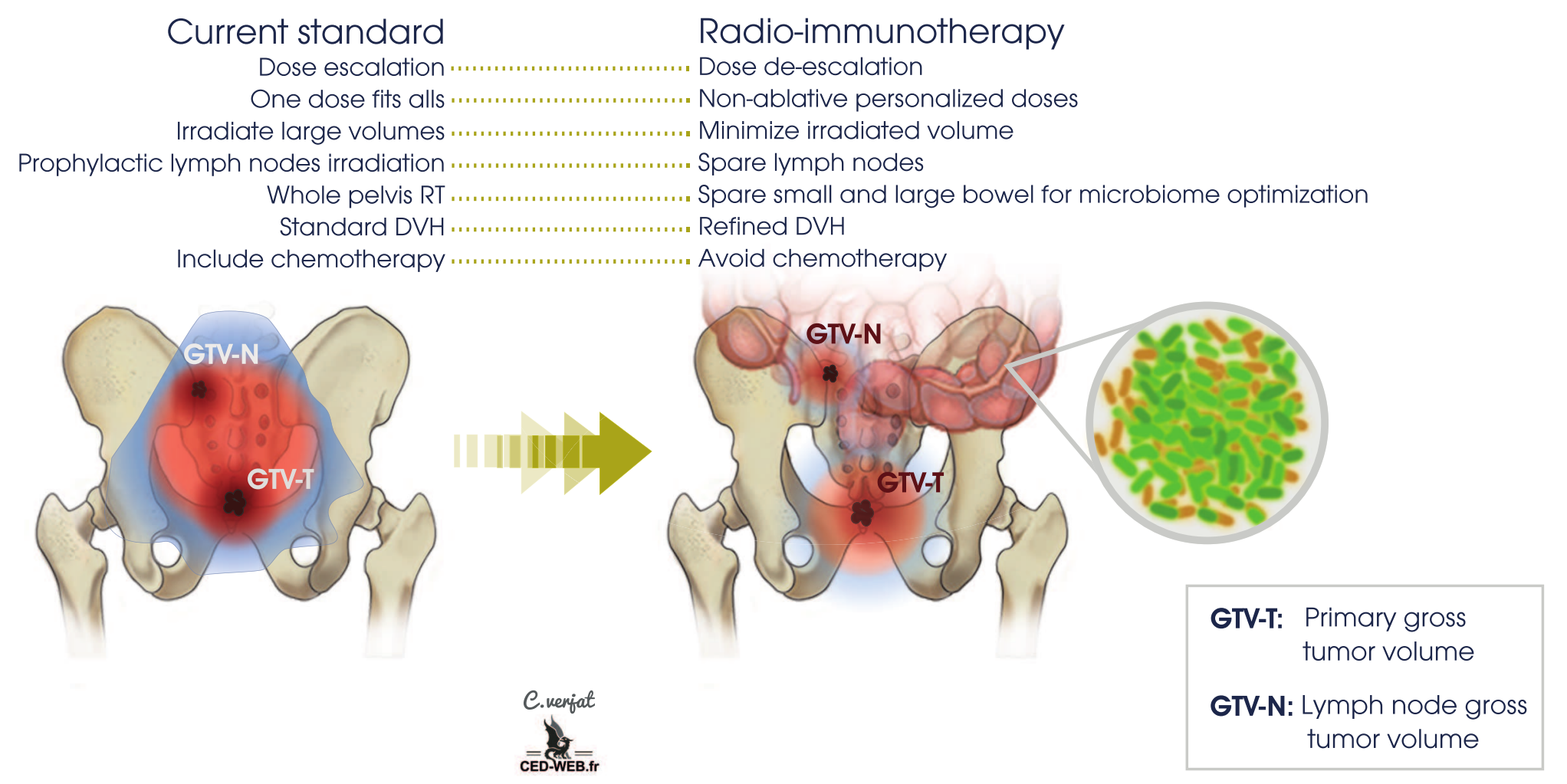


Table 1. Prospective clinical studies assessing radiotherapy in combination with immunomodulatory regimens.

\begin{tabular}{|c|c|c|c|c|c|c|}
\hline Indication and selection criteria & Phase & $\begin{array}{l}\mathrm{N}^{\circ} \text { of } \\
\text { patients }\end{array}$ & $\begin{array}{l}\text { Treatment } \\
\text { modality }\end{array}$ & Toxicity & Efficacy & Ref. \\
\hline $\begin{array}{l}\text { Solid tumors with } \geq 5 \% \text { PD-L1 } \\
\text { expression amongst malignant cells }\end{array}$ & $\mathrm{I} / \mathrm{II}$ & 10 & $\begin{array}{l}\text { Durvalumab } 10 \mathrm{mg} / \mathrm{kg} \mathrm{Q} 2 \mathrm{~W}+\mathrm{RT} \text { (median } \\
\text { dose } 20 \mathrm{~Gy} \text { in median } 5 \text { fractions), given a } \\
\text { median of } 8.5 \mathrm{~d} \text { after last durvalumab. }\end{array}$ & $50 \%$ of RT-related grade 2 AEs. & $\begin{array}{l}\text { In-field: ORR } 60 \% \text { (2/10 CRs, 4/10 PRs); } \\
\text { out-of-field: 10/14 SD, no objective } \\
\text { responses; no abscopal responses. }\end{array}$ & 108 \\
\hline $\begin{array}{l}\text { Stage III, locally advanced, } \\
\text { unresectable non-small cell lung } \\
\text { carcinoma }\end{array}$ & III & 709 & $\begin{array}{l}\text { Conformal RT (54-66 Gy) with } 2 \text { concurrent } \\
\text { platinum cycles + sequential durvalumab } \\
10 \mathrm{mg} / \mathrm{kg} \text { Q2W, initiated within } 6 \mathrm{w} \text { after RT } \\
\text { and continued for up to } 1 \mathrm{y} \text { (or placebo if no } \\
\text { PD during RT). }\end{array}$ & $\begin{array}{l}\text { Serious AEs in } 29.1 \% \text { and } 23.1 \% \text { of } \\
\text { patients in the durvalumab and } \\
\text { placebo groups, respectively. }\end{array}$ & $\begin{array}{l}\text { Median PFS: } 16.8 \text { mo vs } 5.6 \text { mo } \\
(p<0.001) ; \text { median TTD or distant } \\
\text { metastasis: } 23.2 \text { mo vs } 14.6 \text { mo } \\
(p<0.001)\end{array}$ & 12 \\
\hline Advanced solid tumors & $\mathrm{I}$ & 79 & $\begin{array}{l}\text { SBRT to } 2-4 \text { metastases in doses ranging } \\
\text { from } 30 \text { to } 50 \text { Gy in } 3 \text { to } 5 \text { fractions (partial } \\
\text { irradiation of metastases }>65 \mathrm{~mL})+ \\
\text { pembrolizumab initiated within } 7 \mathrm{~d} \text { after } \\
\text { SBRT completion. }\end{array}$ & $\begin{array}{l}\text { Six patients experienced DLT with } \\
\text { no RT dose reductions. }\end{array}$ & $\begin{array}{l}\text { ORR: } 13.2 \% \text {; median PFS: } 3.1 \mathrm{mo} \\
(95 \% \mathrm{CI}, 2.9-3.4 \mathrm{mo}) .\end{array}$ & 71 \\
\hline $\begin{array}{l}\text { Metastatic solid tumors with } \geq 1 \text { lesion } \\
\text { in the liver or lung amenable to SBRT } \\
\text { and } \geq 1 \text { non-contiguous lesion for } \\
\text { monitoring }\end{array}$ & I & 35 & $\begin{array}{l}\text { Ipilimumab ( } 3 \mathrm{mg} / \mathrm{kg} \mathrm{Q} 3 \mathrm{~W} \text { for } 4 \text { doses) in } 5 \\
\left.\text { RT groups: concurrent ( } 1 \mathrm{~d} \text { after } 1^{\text {st }} \mathrm{dose}\right) \text { or } \\
\text { sequential ( } 1 \mathrm{w} \text { after the } 2^{\text {nd }} \text { dose) RT ( } 50 \mathrm{~Gy} \\
\text { in } 4 \text { fractions) to lung or liver, or sequential } \\
60 \mathrm{~Gy} \text { (in } 10 \text { fractions) to lung or liver. }\end{array}$ & $\begin{array}{l}\text { Two patients experienced DLT and } \\
12(34 \%) \text { grade } 3 \text { AEs. }\end{array}$ & $\begin{array}{l}\text { Out-of-field responses amongst } \\
\text { assessable patients: } 3 / 31(10 \%) \text { PR; } 7 / 31 \\
\text { (23\%) clinical benefit (PR or SD } \geq 6 \\
\text { months). }\end{array}$ & 109 \\
\hline Brain metastases from melanoma & $\mathrm{I}$ & 16 & $\begin{array}{l}\text { WBRT or SRS + ipilimumab dose escalated } \\
\text { from } 3 \mathrm{mg} / \mathrm{kg} \text { to } 10 \mathrm{mg} / \mathrm{kg} \mathrm{Q} 3 \mathrm{~W} \text { starting at } \\
\text { D3 of WBRT or } 2 \mathrm{~d} \text { after SRS. }\end{array}$ & $\begin{array}{l}\text { Twenty-one gr 1-2 neurotoxic } \\
\text { effects, with no DLT; } 10 \text { additional } \\
\text { grade } 3 \text { AEs ( } 5 \text { gastrointestinal } \\
\text { toxicities); no grade } 4-5 \text { toxicity. }\end{array}$ & $\begin{array}{l}\text { Median PFS: } 2.5 \text { mo after WBRT, } 2.1 \mathrm{mo} \\
\text { after SRS. }\end{array}$ & 110 \\
\hline $\begin{array}{l}\text { Metastatic castration-resistant prostate } \\
\text { cancer with } \geq 1 \text { bone metastasis } \\
\text { progressing after docetaxel }\end{array}$ & III & 799 & $\begin{array}{l}\text { Bone-directed RT ( } 8 \text { Gy in } 1 \text { fraction) + } \\
\text { ipilimumab } 10 \mathrm{mg} / \mathrm{kg} \text { or placebo Q3W for up } \\
\text { to } 4 \text { doses, starting after RT. }\end{array}$ & $\begin{array}{l}\text { Most common grade } 3-4 \text { AEs were } \\
\text { immune-related ( } 26 \% \text { of the } \\
\text { ipilimumab group, including } 4 \text { toxic } \\
\text { deaths). }\end{array}$ & $\begin{array}{l}\text { Median OS: } 11.2 \text { mo vs } 10.0 \text { mo } \\
(p=0 \cdot 053) \text {; median PFS: } 4.0 \text { mo vs } 3.1 \\
\text { mo }(p<0 \cdot 0001)\end{array}$ & 111 \\
\hline
\end{tabular}




\begin{tabular}{|c|c|c|c|c|c|c|}
\hline $\begin{array}{l}\text { Stage IV melanoma with } \geq 1 \text { non- } \\
\text { irradiated metastasis measuring } \geq 1.5 \\
\mathrm{~cm} \text { available for response assessment }\end{array}$ & I & 22 & $\begin{array}{l}\text { RT to } 1-2 \text { disease sites (BED10: } 23.3 \text { Gy to } \\
72.9 \text { Gy), initiated within } 5 \mathrm{~d} \text { of ipilimumab } \\
\text { initiation (for } 4 \text { cycles). }\end{array}$ & $\begin{array}{l}\text { No unexpected toxicity; } 3 \text { grade } 3 \\
\text { AEs. }\end{array}$ & $\begin{array}{l}\text { Three patients (27.3\%) achieved systemic } \\
\text { CR, and } 3(27.3 \%) \text { an initial PR. }\end{array}$ & 112 \\
\hline $\begin{array}{l}\text { Metastatic castration-resistant prostate } \\
\text { cancer }\end{array}$ & $\mathrm{I} / \mathrm{II}$ & $33 / 50$ & $\begin{array}{l}\text { Ipilimumab Q3W for } 4 \text { cycles at } 3,5 \text {, or } 10 \\
\mathrm{mg} / \mathrm{kg} \text {, or at } 3 \text { or } 10 \mathrm{mg} / \mathrm{kg}+\mathrm{RT}(8 \mathrm{~Gy} \text { per } \\
\text { lesion). }\end{array}$ & $\begin{array}{l}\text { Common grade } 3 \text { immune-related } \\
\text { AEs in patients receiving RT were } \\
\text { colitis }(16 \%) \text { and hepatitis }(10 \%) ; 1 \\
\text { treatment-related death was recorded } \\
\text { (in } 5 \mathrm{mg} / \mathrm{kg} \text { group). }\end{array}$ & $\begin{array}{l}\text { Eight PSA declines } \geq 50 \% \text { (duration: } 3- \\
13+\mathrm{mo} \text { ), } 1 \text { CR (duration: } 11.3+\text { mo), and } \\
6 \mathrm{SD} \text { (duration: } 2.8-6.1 \mathrm{mo} \text { ), amongst } \\
\text { patients treated with RT + ipilimumab } 10 \\
\mathrm{mg} / \mathrm{kg} \text {. }\end{array}$ & 113 \\
\hline $\begin{array}{l}\text { Metastatic solid tumors with } \geq 3 \\
\text { distinct measurable sites of disease }\end{array}$ & II & 41 & $\begin{array}{l}\text { Concurrent RT ( } 35 \text { Gy in } 10 \text { fractions over } 2 \\
\text { w) to } 1 \text { metastatic site and GM-CSF ( } 125 \\
\mu \mathrm{g} / \mathrm{m}^{2} \text { s.c. daily for } 2 \text { weeks, starting during } \\
\text { the } 2^{\text {nd }} \text { week of RT). Course repeated to } \\
\text { target a } 2^{\text {nd }} \text { metastatic site. }\end{array}$ & $\begin{array}{l}\text { Most common grade } 3-4 \text { AEs were } \\
\text { fatigue ( } 6 \text { patients) and } \\
\text { hematological ( } 10 \text { patients); } 1 \text { patient } \\
\text { experienced grade } 4 \text { pulmonary } \\
\text { embolism. }\end{array}$ & $\begin{array}{l}\text { Abscopal responses in } 11(26.8 \%, 95 \% \\
\text { CI 14.2-42.9) of patients. }\end{array}$ & 56 \\
\hline Metastatic melanoma & $\mathrm{I}$ & 22 & $\begin{array}{l}\text { Escalating doses of SBRT ( } 2-3 \text { fractions) to } \\
\text { index lesion, followed } 3-5 \text { d later by } \\
\text { ipilimumab Q3W for } 4 \text { cycles. }\end{array}$ & No DLTs; 15 grade 3 AEs. & $\begin{array}{l}\text { Evaluation non-irradiated targets: } 18 \% \\
\text { PR, and } 18 \% \text { SD. }\end{array}$ & 80 \\
\hline $\begin{array}{l}\text { Metastatic melanoma or renal cell } \\
\text { carcinoma }\end{array}$ & I & 12 & $\begin{array}{l}\text { 1-3 doses of SBRT ( } 20 \text { Gy per fraction), last } \\
\text { dose administered } 3 \text { d before initiation of } \\
\text { high-dose interleukin- } 2 \text {. }\end{array}$ & No DLT attributable to SBRT. & $\begin{array}{l}\text { Evaluation of non-irradiated targets: } \\
1 \mathrm{CR} \text { and } 7 \mathrm{PR} \text {. }\end{array}$ & 114 \\
\hline Glioblastoma & II & 46 & $\begin{array}{l}\text { Surgical resection followed by standard } \\
\text { conformal RT + autologous vaccine } \\
\text { generated from resected tumors and } \\
\text { delivered weekly after RT completion. }\end{array}$ & $\begin{array}{l}\text { AEs attributable to the vaccine in } 34 \\
\text { pts ( } 74 \%) \text {; but no grade } 3-4 \text { AEs } \\
\text { related to vaccination. }\end{array}$ & $\begin{array}{l}\text { Median OS: } 23.8 \text { mo (18.0 mo for } \\
\text { patients with high PD-L1 expression on } \\
\text { myeloid cells } v s .44 .7 \text { mo for patients } \\
\text { with low PD-L1 expression; } p=0.007) \text {. }\end{array}$ & 115 \\
\hline
\end{tabular}

Abbreviations. AE, adverse event; BED10, biologically effective dose (estimated for the tumor); CR, complete response; DLT, dose-limiting toxicity; ORR, objective response rate; OS, overall survival; PD, progressive disease; PFS, progression-free survival; PR, partial response; RT, radiation therapy; SBRT, stereotactic body radiation therapy; SD, stable disease; SRS, stereotactic radiosurgery; TTD, time to death; WBRT, whole-brain RT. 